\title{
The Diverse Effects of Intraspecific Competition on the Selective Advantage to Resistance: A Model and Its Predictions
}

\author{
Arthur E. Weis $^{1,2, *}$ and Michael E. Hochberg ${ }^{3}$ \\ 1. Department of Plant Population Biology, Netherlands Institute \\ for Ecology, Center for Terrestrial Ecology, 6666 ZG Heteren, The \\ Netherlands; \\ 2. Department of Ecology and Evolutionary Biology, University of \\ California, Irvine, California 92697; \\ 3. Laboratorie d'Ecologie, Université de Paris VI, CC237, 7 quai \\ Saint Bernard, 75252 Paris 05, France
}

Submitted October 30, 1998; Accepted April 21, 2000

ABSTRACT: We constructed a model to investigate conditions under which intraspecific competition amplifies or diminishes the selective advantage to resistance. The growth trajectories of competing individual plants were depicted by logistic difference equations that incorporated basic costs (lowered growth rate) and benefits (lowered damage) of defense. Analytical results showed that when competition is absent, resistance is favored by high damage, low cost, and slow growth rate. Competition makes selection more complex. When herbivore damage reduces the size of a susceptible plant, resistant neighbors can usurp its resources and thus suppress its regrowth. This competitive interaction amplifies the relative fitness of the resistants. Numerical simulations explored a broader range of conditions. Three factors were varied: competition mode (symmetric vs. asymmetric), resistance type (damage avoidance vs. damage reduction), and timing of attack (early, mid, or late season). We found that competition mode had drastic effects on outcomes. Under symmetric competition, increased plant density intensified the selective advantage of resistance, damage avoidance was more strongly favored than damage reduction, and resistance to late attack was more favored than to early attack. Asymmetric competition had opposite effects: selection acted against resistance at high density, damage reduction was more strongly favored, and resistance against early attack was more favored. Interestingly, the two competition modes induced opposite patterns of density-dependent selection. The difference between the symmetric and asymmetric cases is explained by the fact that resistance costs during the preattack phase are more strongly amplified by asymmetric competition. When resistance is induced, so that pre-

* To whom correspondence should be addressed; e-mail: aeweis@ uci.edu.

Am. Nat. 2000. Vol. 156, pp. 276-292. (c) 2000 by The University of Chicago. 0003-0147/2000/15603-0005\$03.00. All rights reserved. attack costs of resistance are zero, asymmetric competition more strongly amplified the benefits during the postattack phase. The prediction that selection on resistance will be plant density-dependent has complex implications for the evolutionary dynamics of defense evolution.

Keywords: competition, resistance, costs of resistance, plants, herbivory, model.

Herbivore attack can directly reduce plant fitness, but the magnitude of the effect can depend on the environmental context, including the competitive environment (Clay 1990; Louda et al. 1990). Harper (1977) noted that damaged plants can lose standing in the local size hierarchy, and as a consequence, postattack competition can compound the negative effects of damage. The interaction between "interspecific" competition and herbivory (or infection) has the potential to influence community structure (Crawley 1983; Louda et al. 1990); however, experimental studies have not found consistently compounding effects of herbivory and interspecific competition (Grove and Williams 1975; Bentley and Whittaker 1979; Rausher and Feeny 1980; Fowler and Rausher 1985; Parker and Salzman 1985; Cottam 1986; Cottam et al. 1986; Maschinski and Whitham 1989; Reader 1992; Steinger and Muller-Scharer 1992; McEvoy et al. 1993; Frost and Ryding 1997; Maron 1997; van der Putten and Peters 1997; Notzold et al. 1998).

When considering the interaction of herbivory and "intraspecific" competition, however, the loss in growth and fitness caused by damage is quite frequently amplified in high-density stands (Windel and Franz 1979; Lee and Bazzaz 1980; Burdon et al. 1984; Hjälten et al. 1993; Verwijst 1993; Shabel and Peart 1994; Lively et al. 1995; Mutikainen and Walls 1995; Kelly 1996; Augner et al. 1997; Marbry and Wayne 1997), although counterexamples have been found (Edenius et al. 1993; Karban 1993; Parmesan 2000). The contrast between the inter- and intraspecific cases may come about because competitors of the same species have more similar resource requirements than those of different 
species, or, tend to be intraspecifically aggregated (Dytham and Shorrocks 1995).

This article explores the ways in which natural selection for resistance genes will be modified when intraspecific competition compounds the negative fitness effects of damage. Individuals with resistant genotypes will benefit because they will receive less damage on average, but in addition, they will have access to resources that their damaged, susceptible neighbors are unable to exploit. Conversely, susceptible genotypes not only lose tissue to their enemies but also have the resources needed for recovery usurped by resistant neighbors. The compounding effect of competition with damage can thus amplify the selective advantage to resistance (Windel and Franz 1979; Burdon et al. 1984; Verwijst 1993; Augner et al. 1997).

Just as intraspecific competition can amplify relative "benefits" of resistance, it may also amplify relative resistance "costs" (Coley 1987; Karban and Baldwin 1997). Direct trade-offs between resistance to parasites and competitive ability have been demonstrated in taxonomically diverse systems (e.g., Price et al. 1986; Lenski 1988; Kraaijveld and Godfray 1997). Theory predicts that plants allocating resources to defense will grow more slowly (Herms and Matson 1992; Zangerl and Bazzaz 1992), as shown in some cases (but see Basey and Jenkins 1993; Niemann et al. 1995; Sagers and Coley 1995; Bergelson and Purrington 1996). For instance, Brassica rapa lines selected by Mitchel-Olds and Bradely (1996) for resistance to fungal attack showed a $6 \%$ decrease in growth rate. Slow growth can put resistant plants at the bottom of the size hierarchy, where competition can then slow growth even further. Several experiments have shown that resistance costs are amplified by stressful conditions (Bergelson 1994), although too few studies have been conducted to draw general conclusions (Bergelson and Purrington 1996). A competitive cost of plant resistance can be inferred from studies that show increased defense costs under resource limitation (Vrieling and van Wijk 1994), as well as by analogy to cases where competition amplifies the cost of herbicide resistance (Williams et al. 1995) and the intensity of inbreeding depression (Schmitt and Ehrhardt 1990). Recently, Augner et al. (1997) investigated resistance and competition in two strains of the European birch. The unpalatable strain grew slower in the absence of competition, and this deficit was magnified when it was grown in competition with the palatable strain. In a different vein, van Dam and Baldwin (1998) showed that undefended tobacco plants are more successful competitors against defended plants then against other undefended ones.

We initiated a modeling project to explore the ways that competition between resistant and susceptible genotypes changes the direction or intensity of selection on resis- tance. Four basic questions were addressed: Are there qualitative differences in the effects of competition on selection for different resistance types, that is, for resistance factors that reduce the probability of attack ("damage avoidance") and those that reduce herbivore feeding after an attack begins ("damage reduction")? Does selection intensity on resistance change as the plant size hierarchy develops over the course of the growing season? Do different modes of competition, specifically symmetric versus asymmetric, have qualitatively different effects on resistance selection? And is the effect of competition on selection the same for constitutive resistance (resistance mechanism expressed throughout ontogeny) as it is for induced resistance (resistance mechanism expressed only if damage occurs)?

\section{The Model}

We present our model in terms of selection acting on a genotype that codes for defense structures such as secondary chemicals or leaf hairs. These defenses are assumed to impose a metabolic cost that reduces growth rate. The model can also be applied to cases in which herbivores preferentially feed on plants with high growth rate (because of their superior nutritional value), as is posited by the plant vigor hypothesis of Price (1991).

\section{Ecological Foundations}

We modeled the fitness effects of resistance to herbivory within the framework of competitive size hierarchies (Weiner 1985; Bonan 1991; Schwinning and Weiner 1998). The model examined the relative performance of resistant and susceptible genotypes of an annual plant species when exposed to herbivore attack at a single point in the growing season. "Resistant" and "susceptible" are used as relative terms; the former can be attacked and damaged but to a lesser extent than the latter. We assumed that plants compete for the same limiting resources before, during, and after attack. Competition intensity is proportional to the size and density of plant neighbors. As a particular focal plant grows over the course of a season, it imposes increasing suppressive effects on its neighbors. In turn, neighbors suppress the focal plant as they grow.

Under these conditions, a plant ascending to the top of the neighborhood size hierarchy early in the growing season is likely to maintain a superior position throughout. However, herbivore damage can send a plant to the bottom of the size hierarchy, putting it at a competitive disadvantage. Resistant plants get less damage and so potentially avoid this fate. The improved standing in the postattack local size hierarchy can thus amplify the basic benefits of resistance.

Competition can also amplify resistance cost. If the pro- 
duction of a resistance factor lowers growth rate, resistant plants will be smaller than their susceptible neighbors during the preattack period. This reduced size could make them more prone to suppression by neighbors and less able to exert a countering-acting suppressive effect. During the postattack period, slower growth in resistant plants could lead to slower recovery from whatever damage they receive.

\section{Model Formulation}

Our model of resistance and competition is based on a simple difference equation for logistic growth of plant individuals. In the absence of competitors and herbivores, plant growth is described by the equation

$$
M_{t+1}=\frac{M_{t}+\rho M_{t}}{1+\theta_{F} M_{t}}
$$

where $M_{t}$ is the biomass of the focal plant at time $t, \rho$ is the maximum growth rate, and $\theta_{F}$ is a constant depicting the effects of self-limitation (Iwasa and Kubo 1997). In metabolic terms, $\rho$ relates to photosynthate production available for growth and maintenance, while $\theta_{F}$ relates to maintenance costs and self-shading. Over a sufficiently long season, plants would grow to an asymptotic size of $\rho / \theta_{F}$.

The effects of competition are modeled by including an additional term for the limiting effects of neighbors, such that

$$
M_{t+1}=\frac{M_{t}+\rho M_{t}}{\left(1+\theta_{F} M_{t}\right)\left(1+\sum \delta_{N}^{-1} \theta_{N} M_{N, t}\right)},
$$

where $M_{N, t}$ is the size of neighbor $N, \theta_{N}$ represents the reduction in focal plant growth per unit biomass of the neighbor, and $\delta_{N}$ is the distance to neighbor $N$ (so that the mean of $\delta^{-1}$ is proportional to plant density).

Herbivory is modeled by multiplying the numerator $\left(M_{t}+\rho M_{t}\right)$ by the factor $\left(1-D_{t}\right)$, where $D_{t}$ is the proportion of plant biomass removed from the focal plant during interval $t$. For a defended plant, the damage sustained during a time interval is $D_{t}^{\prime}=D_{t} \times(1-R)$, where $R$ is the proportion reduction in damage suffered by resistant genotypes. The larger the value of $R$, the greater is the benefit of resistance. After damage, plants resumed growth under the same rules as during the preattack period. Thus, the higher basic growth rate of susceptibles also enhanced their regrowth (see Sun 1992).

Allocation to defense can reduce growth rate, and so we quantify costs with the function

$$
\rho_{R}=\rho(1-c R)
$$

where $c$ is the proportionate reduction in base growth rate per unit increase in resistance. Metabolically, this relates to the fact that photosynthate allocated to defense is not available for growth and maintenance. We assume a linear relationship between resistance level and the cost of resistance. Other models have shown that linear and nonlinear cost functions can lead to different optimal levels of defense at evolutionary equilibrium (Frank 1994). Since we are interested in the interaction of competition with selection on resistance within a single generation, we limit our investigation to the simple linear case.

\section{Model Solutions}

We explored shifts in the balance between resistance costs and benefits as a function of damage level and plant density. Analytical solutions could be made or approximated for some very simplified conditions. Complex situations were explored through numerical simulation.

General Simulation Structure. For the basic simulations, we developed a spatially explicit cellular automaton model. Each cell represented a site occupied by a plant (all sites occupied). The grid was populated with equal proportions of two genotypes, susceptible and resistant, randomly assigned to grid points. Assuming that plant fitness is directly proportional to final plant size, we calculated the selection intensity on resistance as

$$
I=\frac{M_{R}-M_{s}}{M^{*}}
$$

where $M_{R}$ and $M_{s}$ are the mean final biomasses for the resistant and susceptible genotypes, respectively, and $M^{*}$ is the population mean final biomass. Negative values of $I$ indicate selection favors the susceptible genotype, whereas positive values indicate resistance is favored.

Within a run, plant size was affected by deterministic factors $\left(R, c, \rho, \theta_{F}, \delta\right.$, and $\left.\theta_{N}\right)$ and random factors (neighbor genotype, the probability of discovery by herbivores, and random variation in initial size). The model was probed using a large array of parameter values (table 1). We used a simulated season of 35 time intervals, with all damage occurring during one time interval. The base growth rate used in the simulations we present is 0.3 per time interval. Increasing growth rate had the same effect as lengthening the season length, while slower rate had the same effect as a short season. Direct comparison of this growth rate to those measured for natural species (e.g., Hunt and Cornelissen 1997) is problematic because of the differences in time units (days vs. arbitrary units) and uncertainties of 
Table 1: Definition of model parameters, and values used in simulations

\begin{tabular}{|c|c|c|c|}
\hline Parameter & Definition & Range & Comments \\
\hline$\rho$ & Basic growth rate & $.2-.4$ & $\begin{array}{l}\text { Mass added per unit mass, and related to photosynthate } \\
\text { production. Value of } .3 \text { used in all reported simu- } \\
\text { lations. Increasing } \rho \text { increased regrowth rate, } \\
\text { making resistance less favorable. }\end{array}$ \\
\hline$M_{0}$ & Starting mass & Held at 1.0 & $\begin{array}{l}\text { Effects of random variation }(\mathrm{CV}=20 \%) \text { had no quali- } \\
\text { tative effect. }\end{array}$ \\
\hline$\theta_{F}$ & Self-limitation constant & $.0005-.002$ & $\begin{array}{l}\text { Related to maintenance costs and self-shading. Value of } \\
.001 \text { used in all simulations presented here. } \\
\text { Increasing and decreasing value leads to decreasing } \\
\text { and increasing final size, respectively. }\end{array}$ \\
\hline$\theta_{N}$ & Competition coefficient & $.0005-.002$ & $\begin{array}{l}\text { Value of } .001 \text { used in all simulations presented here. } \\
\text { Increasing } \theta_{N} \text { relative to } \theta_{F} \text { generally intensifies selec- } \\
\text { tion and in some cases can cause reversals in } \\
\text { direction in the same way that increasing density can. }\end{array}$ \\
\hline$\delta$ & Interplant distance & $.327-100$ & The inverse of $\delta$ is proportional to plant density. \\
\hline$D$ & Damage level & $0-.8$ & $\begin{array}{l}\text { Proportion of mass removed from susceptibles. At any } \\
\text { level of } D \text {, the proportion of mass removed from } \\
\text { resistants is } D(1-R) \text {. }\end{array}$ \\
\hline$R$ & Resistance level & $0-.8$ & Proportion reduction in damage suffered by resistants. \\
\hline C & Resistance cost coefficient & $0-.32$ & $\begin{array}{l}\text { Resistance costs reduce basic growth rate, } \rho \text {, by a factor } \\
\text { of }(1-c R) \text {. }\end{array}$ \\
\hline
\end{tabular}

Note: $\mathrm{CV}=$ coefficient of variation.

season length and strength of self-limitation in the natural species. The 0.3 growth rate and the 0.001 self-limitation constant yielded a realistic sigmoid growth curve that reached $95 \%$ of the asymptotic size in the 35 unit season. The range of herbivory levels tested went from $0 \%$ to $80 \%$ of plant tissue removed, which should span most natural situations. To provide a basis for comparison when analyzing competitive effects, the competition coefficient, $\theta_{N}$, was held equal to $\theta_{F}$. Interplant distance was varied between runs; distances were manipulated to generate competition levels between neighbors that were as low as $1 \%$ of self-limitation in the lowest competition runs to twice the strength of self-limitation in the highest competition runs. We found that by varying the above parameter values, the model outcomes varied quantitatively but not qualitatively. Here we present representative runs.

Spatial Arrangement of Competitors. Simulated plant sites were located on a uniformly spaced hexagonal grid. Each plant competed with its six immediate neighbors. At a grid spacing of 1.0, the competitive effect of a neighbor on focal plant growth was equal to the focal plant's selflimitation. No direct competitive effects with more distant neighbors were modeled, but indirect effects emerged from the model structure. For instance, a very large plant two grid units away from the focal plant would suppress the intervening neighbor that in turn would exert only a weak suppressive effect on the focal plant. To avoid edge effects, plants along one edge were treated as neighbors of plants on the opposite edge, thus creating a virtual torus. We used grids of 324 to 1,296 cells. Introducing variance in initial plant size increased within-genotype variance, but there was no noticeable change in relative genotypic means in final size. We assume that variance in interplant distance would have the same effect.

Resistance Types. Two resistance types were considered. Damage avoidance lowered the probability of attack but not the amount of herbivore consumption if an attack occurred. Damage reduction had no effect on attack probability but curtailed herbivore consumption.

When modeling damage avoidance, we assumed that plants were encountered by herbivores with probability $a$. Susceptible plants were always accepted upon encounter, but resistant plants were rejected with a probability $R$. Once accepted, a constant proportion, $C$, of the biomass was consumed. Thus, the average proportion damage sustained was

$$
\begin{aligned}
D_{s} & =a C, \\
D_{R} & =(1-R) a C,
\end{aligned}
$$

for the susceptible and resistant genotypes, respectively.

In contrast, with damage reduction we assumed all plants were encountered $(a=1.0)$ and all encounters resulted in attack. However, the proportion of biomass re- 
moved, $C$, was lower for resistant than susceptible plants by a factor of $(1-R)$. The mean damage for the two genotypes under damage reduction are also given by equations ( $5 a)$ and (5b), except in this case $a$ is assumed to be constant and $C$ variable - the reverse of the damage avoidance case. With this formulation, we could contrast the effectiveness of the two resistance types while holding mean damage levels constant. Note that damage avoidance leads to a bimodal distribution of postattack plant sizes (attacked and not attacked) within each genotype and so increased size variance. Damage reduction did not by itself change size variance.

Competition Modes. Size-symmetric and size-asymmetric competition modes (Miller and Weiner 1989; Schwinning and Weiner 1998) were considered. With symmetric competition, each neighbor exerted a suppressing effect on the focal plant in proportion to its own size, that is, $\theta_{N} M_{N, t}$. Gross competitive effects are not equal since a larger plant will have a greater effect on a smaller one than vice versa, but competition is symmetric in the sense that the effect exerted by large and small plants is the same on a per unit mass basis. Several studies (e.g., Goldberg 1987) have concluded that for some species, competitive effects are symmetric on a per unit mass basis. Others have argued that competition may frequently be unequal on a per unit mass basis (Weiner 1990; Schwinning and Weiner 1998). For instance, when competing for light, a taller plant can cast a shadow over a shorter one, but a shorter plant casts no shadow over a taller one. We simulated asymmetry by making the competition coefficient a logistic function of the size difference between the focal and neighbor plants (Law et al. 1997):

$$
\theta_{\text {asym }}=\theta_{N}\left[1-\frac{1}{1+\exp \left(M_{F}-M_{N}\right)}\right] \text {, }
$$

where $M_{F}$ and $M_{N}$ are the sizes of the focal and neighbor plants at the beginning of the time interval. When the focal plant is much smaller than the neighbor, $\theta_{\text {asym }} \cong \theta_{N}$, whereas $\theta_{\text {asym }} \cong 0$ in the reverse situation. With asymmetric competition, the effect of a neighbor plant on a focal plant was thus determined by both neighbor size and by the size difference (i.e., $\theta_{\text {asym }} \times M_{N, t}$; see eq. [2]). At high densities, asymmetric competition can lead to bimodal size distributions.

\section{Results}

Analytical solutions to the model were possible only when several restrictive assumptions were made, such as resistance comes through damage reduction and competition is symmetric. We will not report details of the analytic solutions here but rather state the two main conclusions. First, assuming a finite growing season, no competition, and exponential plant growth, resistance is more favored when costs are low, damage is high, or base growth rate is low (see Coley et al. 1985). Under these conditions, the damaged, susceptible plants are unlikely to regrow enough to overtake the undamaged resistants before season's end, and so resistance is favored. Second, under competition, resistance tends to be favored if the size ratio of the resistants to the susceptibles is large compared to the ratio of competitive effect to self-limitation. The simulations illustrate the importance of the postattack sizes of resistants and susceptibles.

\section{General Effect of Competition on Costs and Benefits of Resistance}

We conducted extensive simulation studies to investigate selection under a variety of situations. Our most basic result is that competition can amplify both costs and benefits of resistance. Figure 1 shows a typical case in which the final size differences between resistant and susceptible plants are proportionately greater in high-density runs than under low density. Before detailing the results in figure 1 , we wish to explain several of its features that recur in subsequent figures. The results of 22 different simulation runs are presented-11 runs with different herbivory levels at each of two different plant densities. Each model run is of a single generation (one growing season). For each level of damage on the $X$-axis, the two corresponding values of biomass on the $Y$-axis are the means for resistant and susceptible plants in one run. Increasing plant density (quantified by $\delta^{-1}$ in eq. [2]) is equivalent to decreasing intraplant distances, with the effect of increasing competition intensity. The axis for herbivory level is labeled "damage (to susceptibles)." A value of say 0.64 means that $64 \%$ of susceptible plant biomass was consumed during attack. The damage inflicted on resistant plants is (1 $R$ ) of that on susceptibles. In this series of runs $R=0.8$, so that when $64 \%$ damage was inflicted on susceptibles, only $12.8 \%$ was inflicted on resistants. As with all figures, the parameter values used are given in the caption.

The general effect of competition was to intensify selection on resistance (fig. 1). In the absence of herbivory, where selection acts only through resistance costs, the selection intensities against the resistant genotype were -0.11 and -0.26 at low and high densities, respectively. At the highest damage level, selection favored the resistant genotype with an intensity of 0.31 at low density but of 1.01 at high density. Thus, the intensity of selection on resistance is density dependent. These simulations depict the simple case of symmetric competition and resistance 


\section{A. Low Plant Density}

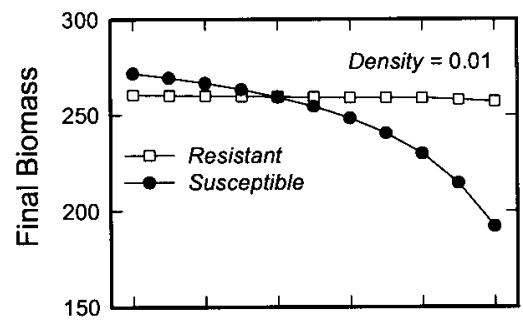

\section{B. High Plant Density}

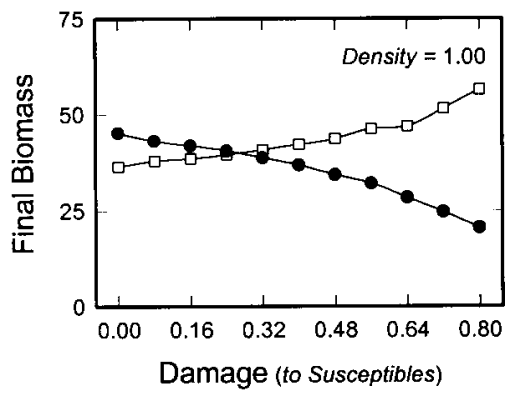

Figure 1: Mean final biomass of resistant and susceptible genotypes exposed to increasing levels of herbivory. Competition is symmetric. Attack occurred at the 25 time interval (of 35). Resistance level, $R$, set to 0.80 ; cost coefficient, $c$, set to 0.04 ; and $C V$ of starting size set to 0.0 . Note that resistant plants, by definition, received $80 \%$ less damage. Thus, when susceptibles had $80 \%$ of their mass removed, resistants had only $16 \%$ removed. $A$, Competition weak. Interplant distance was 100 units, leading to a density of 0.01 . Both genotypes show a decline in final size. $B$, Competition strong, with interplant distance of 1 , leading to a density of 1.0. Although the size of susceptibles declines with damage, that of resistants increases.

through damage reduction, but they illustrate the principals at work in more complex cases.

Competition intensifies the benefits of resistance because undamaged plants can usurp resources that would otherwise go to their damaged neighbors. Compare figure $1 A$ to $1 B$. At low density, the growth performance of the resistants is slightly reduced at high herbivory levels (fig. $1 A)$. At high density, in contrast, the growth performance of resistant plants actually increases with damage levels (fig. 1B). This would appear to be a case of overcompensating growth (Paige and Whitham 1987) but is in fact a case of competitive release. Intense herbivory sends susceptibles to the bottom of the size hierarchy and so relieves the less-damaged resistants from competition.

Growth curves in figure 2 illustrate how a postattack size advantage of resistant plants can be parlayed into a competitive advantage. Since plants have logistic growth, their net growth rate $\left(\Delta M / M_{t}\right)$ declines linearly with size $\left(M_{t}\right)$. Consider first what happens at low plant density, where competition is negligible. Herbivory reduces the plants from size $M_{\mathrm{b}}$ (mass before attack) to a smaller size $M_{\mathrm{a}}$ (mass after attack). When plants resume growth, they grow at the higher net growth rate that is specific to size $M_{\mathrm{a}}$. At some earlier point in the plant's life it was also at size $M_{\mathrm{a}}$, and its net growth rate at that earlier time was the same as during the interval after attack (fig. $2 A$ ). At low density the susceptible plants regrow unfettered by competition with their less-damaged resistant neighbors and so can make up for most of the damage they receive (see Oesterheld and McNaughton 1991).

At high density, however, the postattack size advantage of resistant plants allows them to suppress their damaged susceptible neighbors. When a susceptible plant is reduced from size $M_{b}$ to size $M_{a}$, it resumes growth but at a lower rate than it had when at size $M_{a}$ earlier in the season (fig. $2 B$ ). This is because suppression by resistant plants pushes susceptibles onto a slower growth trajectory. Conversely, when damage to a susceptible neighbor releases a resistant plant from competition, the resistant plant is pushed onto a faster growth trajectory (fig. $2 B$ ).

The results of this section illustrate the principle that resistant plants can profit from the misfortune of their damaged neighbors (Augner et al. 1991, 1997). The following sections show the degree of benefit depends on resistance type, competition mode, and timing of attack.

\section{Selection on Resistance with Size-Symmetric Competition}

In this section we present four results on the advantage of resistance when plants compete symmetrically. The results are as follows: resistance tends to be more strongly favored under competitive conditions; damage avoidance is generally superior to damage reduction resistance; the advantage of resistance against late-season attack is generally greater than that against early season attack; and both the intensity and direction of selection can change with the timing of attack, but generally there is positive density dependent selection for resistance. All results emerge from an interaction among the size difference between genotypes after attack, the intensity of competition during the postattack period, and the amount of time available for regrowth.

As indicated in the previous section, competition can increase both the benefits and costs of resistance. This is illustrated in figure 3 , which shows the results of two sets of 168 runs across an array of damage and density levels. In these runs herbivore attack occurred during interval 20 (of 35) when absolute growth rate was close to its highest (see fig. 2). Resistance level was set to $R=0.5$ and the cost coefficient to $c=0.02$ (maximum growth rate of resistants was $1 \%$ less than susceptibles). The white portions of the surfaces plotted in figure 3 indicate herbivory-density 


\section{A. Low Plant Density}
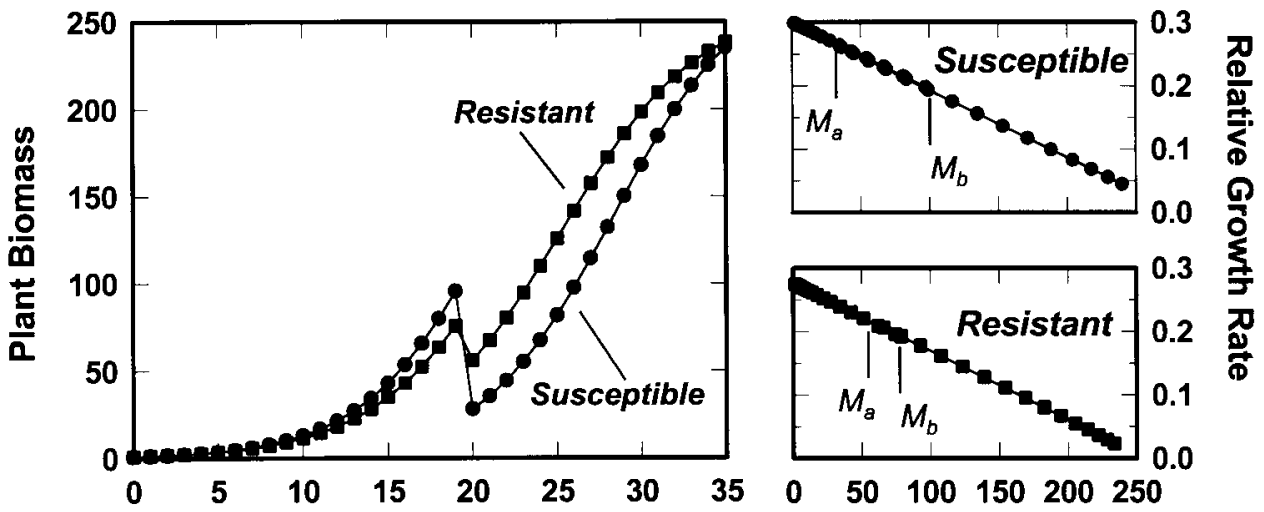

\section{B. High Plant Density}
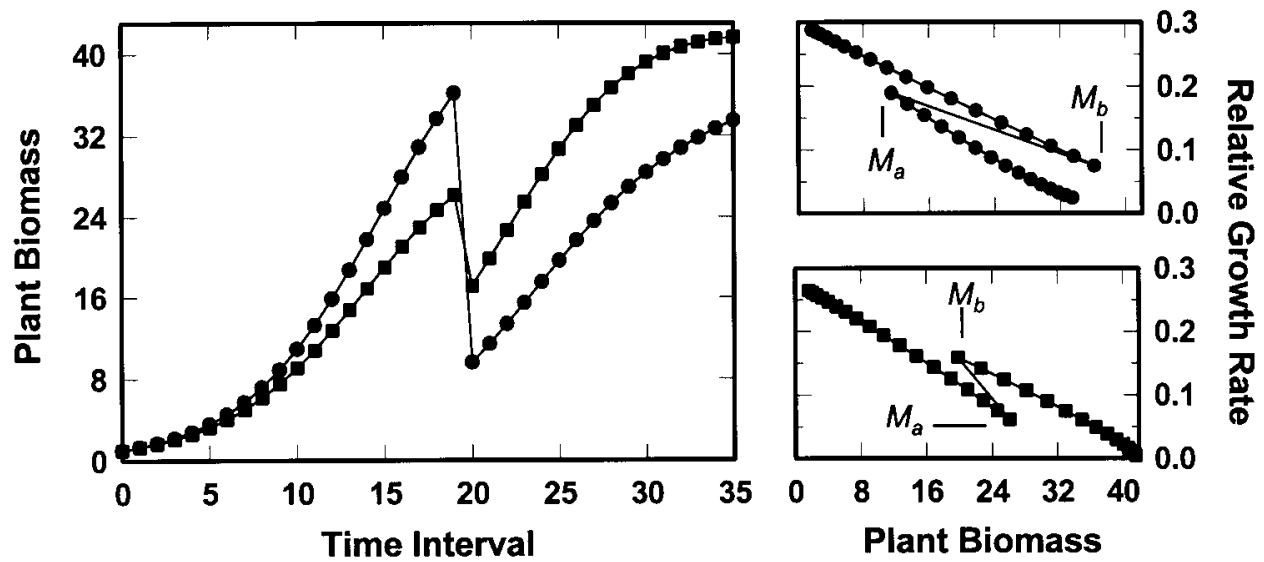

Figure 2: Growth curves of resistant and susceptible genotypes, with net growth rates as a function of size. Damage level (for susceptibles) was $0.80, R=0.8, c=0.16$, and $\mathrm{CV}=0 . M_{b}$ is the biomass before attack, and $M_{a}$ is the mass immediately after attack. $A$, Low plant density $(0.01)$ leading to low competition. The growth after attack follows the same trajectory as before attack. $B$, High plant density (1.0) leading to strong competition. The size advantage of susceptibles before attack allows them to suppress resistants. After attack, resistants have the size advantage and suppress susceptibles. Therefore, the two genotypes shift growth trajectories after attack.

combinations where the resistant genotype is favored $(I>0)$, whereas shaded portions indicate the susceptible genotype is favored $(I<0)$. The contour where selection changes sign (the white-shade border) is referred to as the "payback contour," that is, where benefits equal costs. Clearly in figure 3, the selective advantage or resistance increases with both herbivory level and plant density. The "twist" in the surfaces shows these two factors have multiplicative fitness effects.

At all density-damage combinations examined, selection more intensely favors the damage avoidance resistance type than the damage reduction (fig. $3 A$ vs. $3 B$ ), and competition amplifies this advantage. When resistance operates through damage reduction (fig. $3 B$ ), all plants are reduced by herbivory. As a result, a focal plant is surrounded by individuals of similar size to itself, and so every plant experiences a similar postattack competitive environment. The more damaged susceptibles are still large enough to have a small suppressive effect on their resistant neighbors. Herbivore attack generates far greater size disparities when resistance occurs through damage avoidance (fig. $3 \mathrm{~A}$ ) because damage causes a strongly bimodal distribution of plant sizes. The bottom mode contains the susceptible plants that were discovered and accepted, which are then severely damaged (reduced by $30 \%$ in fig. 3 ). The upper mode contains the other plants that either go undiscovered or are rejected after discovery. All resistant plants are in the upper mode, and so more resistants win more local competitive contests; because resistance confers a large size advantage, they win by big margins. Damage avoidance 


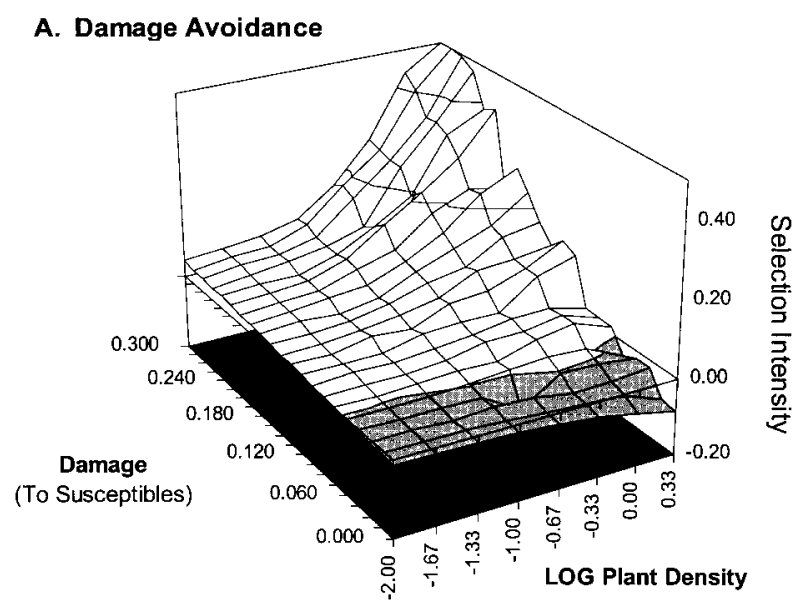

B. Damage Reduction

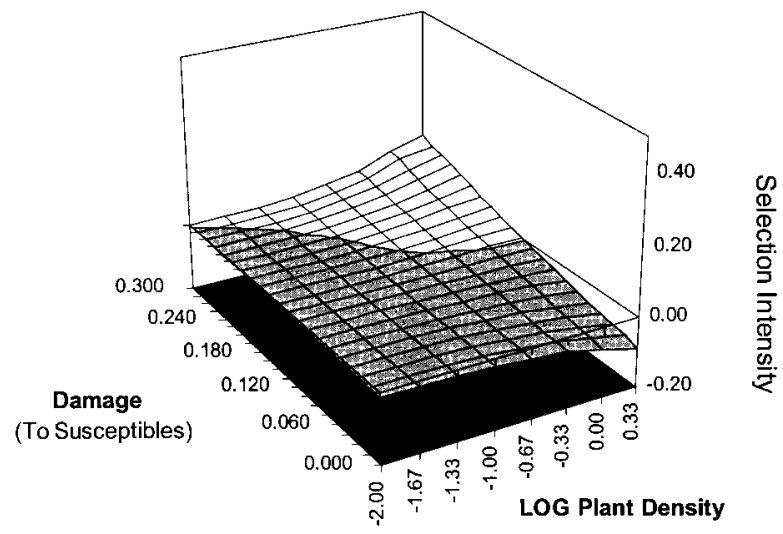

Figure 3: Selective advantage of resistance across a range of densities and herbivory levels. Competition is symmetric. The white areas of the surface denote density-damage combinations where resistance is favored, whereas the shaded areas are those where susceptibility is favored. The white-shade border denotes the payback contour, where benefits and costs are equal. Parameter levels: $R=0.50, c=0.2, \mathrm{CV}=0$. Attack during interval 20. A, Resistance achieved by damage avoidance (see text). $B$, Resistance achieved by damage reduction.

thus leads to a bimodal distribution of final sizes within genotypes, while damage reduction does not (fig. 4).

The density-dependent reversals in selection seen in figure 3 are our second result. Interestingly, densitydependent reversals are stronger for damage reduction resistance than avoidance. There is a broad range of herbivory levels that select against resistance at low density but in its favor at high densities (fig. $3 B$ ). Resistants and susceptibles are of similar postattack size in this damage range, and so density ( $\delta^{-1}$, eq. [2]) is a proportionately greater determinant of competition intensity. The large postattack size disparities generated by damage avoidance resistance relegates density to a lesser role in determining competition intensity and leads to weaker density-dependent reversals in selection (fig. $3 A$ ).

Our third result is that late season attack is more likely to favor resistance than earlier attack. This trend is illustrated in figure 5, which plots the payback contours from simulations where the same proportional level damage was inflicted at different time intervals in the season. The area between the $X$-axis and the contours represent competition-damage combinations where susceptibility is favored, while resistance is favored at combinations above the contours. For both damage avoidance and damage reduction, a lower damage level is required to tip the selective balance in favor of resistance when attack occurred late in the season. Two factors make susceptible plants better able to recover and overtake their resistant counterparts when attack is early. First, when plants are young and growing exponentially, a loss of say $30 \%$ of current mass represents a loss of the growth over only the last one or two time intervals. Second, with early attack there is still sufficient time to make up that lost growth. Resistant plants lose less, but they regrow at a slower rate because of resistance costs and so can still end the season at a smaller size. The situation was different with late attack. Net growth rate slows as a plant gets larger (fig. 2), and so a loss of $30 \%$ current mass late in the season represents the loss of growth achieved over many time intervals. Consequently, more time is required to make up that loss, but because attack is late, less time is available. The timing effect is more pronounced for damage reduction resistance than damage avoidance because only a fraction of plants are attacked in this case.

Returning to figure 5, we point out the fourth result, that is that the timing of damage had a large effect on selection at low density and virtually no effect at high density. When plants are widely spaced, competition is low and plants can continue to grow late into the season (fig. $2 A)$. This gives susceptible plants the opportunity to recover when damage is early, making resistance less favorable. The later the damage, the less recovery time, increasing the advantage to resistance. At high density, however, competition causes net growth rate to decline at a rapid rate (fig. $2 B$ ) so that all plants stop growing earlier in the season. This also reduces the opportunity for regrowth no matter how much time is available for recovery.

\section{Selection on Resistance with Size-Asymmetric Competition}

This section explores the effects of asymmetrical competition on selection for resistance. We assume that if a plant is larger than its neighbor, it exerts a competitive effect proportional to its size. However, if the plant is smaller 


\section{A. Symmetric Competition}

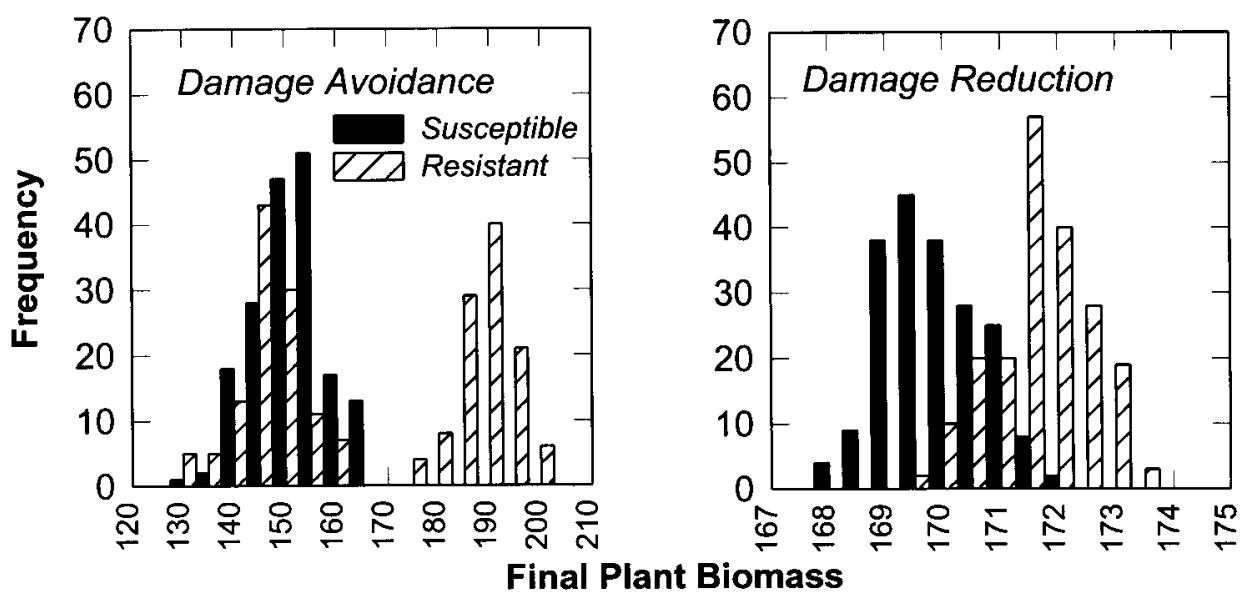

\section{B. Asymmetric Competition}
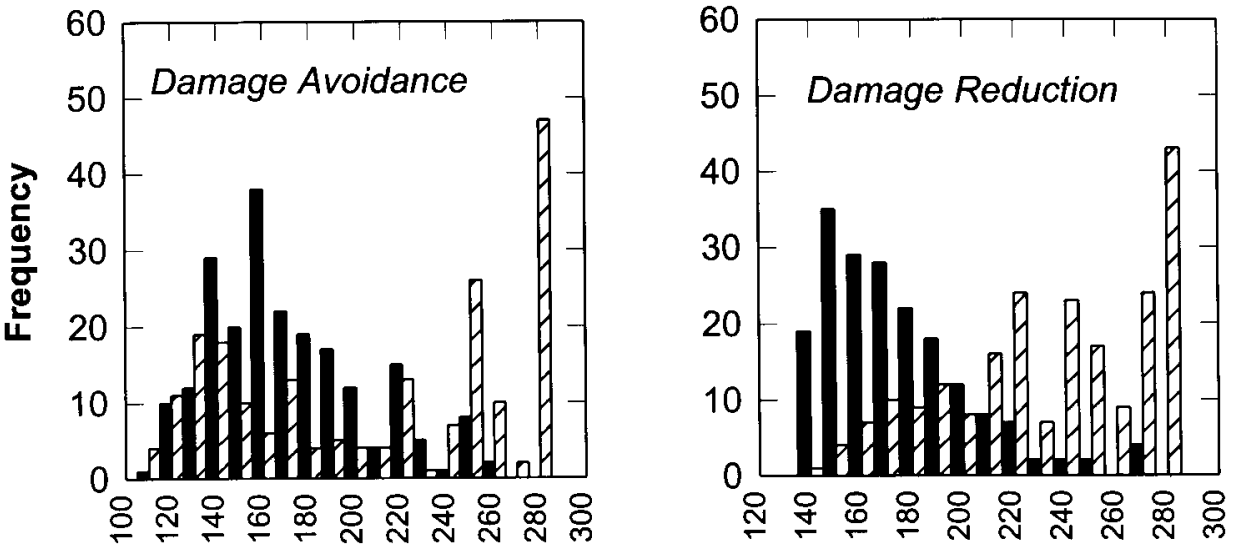

Final Plant Biomass

Figure 4: Size distributions of individuals of resistant and susceptible genotypes under different types of resistance and modes of competition. Parameter levels: $R=0.50, c=0.2, \mathrm{CV}=10, \mathrm{D}=0.30$, and interplant density $=10$. Attack during interval 20. A, Two resistance types under symmetric competition. Damage avoidance leads to a bimodal distribution of final sizes within the susceptible genotypes but not damage reduction. $B$, Two resistance types under asymmetric competition. Competition itself leads to a bimodal distribution of sizes that is little changed by damage avoidance. Damage reduction can reduce the bimodality within genotypes, but strongly increases skew.

than its neighbor, it exerts no effect. Thus, a small size advantage early in the season leads to a big advantage later.

We found that asymmetric competition drastically changes patterns of selection on resistance: strong asymmetric competition tends to select against resistance; damage avoidance becomes inferior to damage reduction resistance; the advantage of resistance is greater for earlyseason attack than late-season attack; and, although the direction of selection can change with attack timing, there is a tendency for asymmetric competition to cause negative density-dependent selection on resistance.

These differences from the symmetric competition case all emerge from the fact that asymmetric competition amplifies resistance costs earlier in the growing season. When competition is symmetric, a small preattack size advantage of a susceptible plant over a slow-growing resistant neighbor leads to a small net competitive advantage: the competitive effect of the larger is countered in part by the 


\section{A. Damage Avoidance}

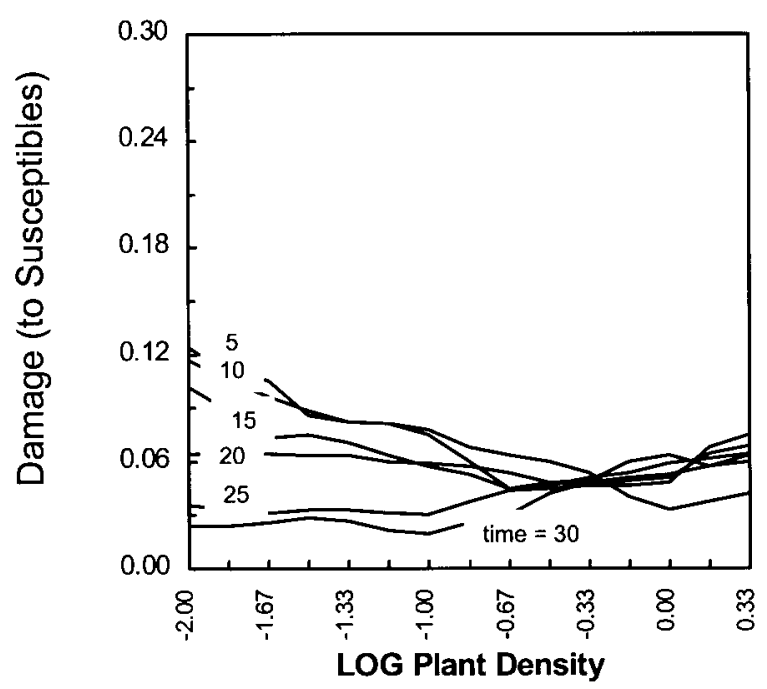

B. Damage Reduction

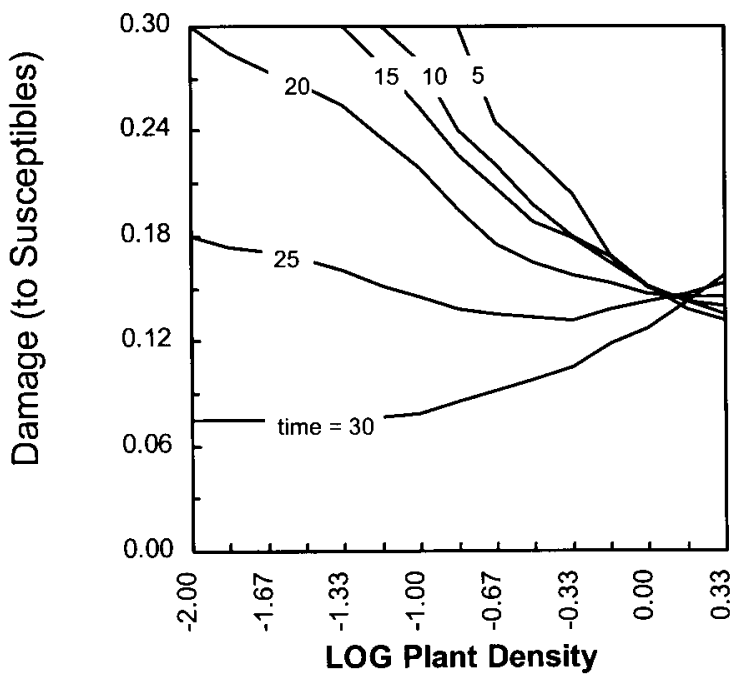

Figure 5: Payback contours (where benefits of resistance equal costs) when attack occurs at different time intervals. Competition is symmetric. Parameter values as in figure 3 except for the time interval of attack, which is indicated for each contour. Selection acts against resistance in the area below each contour (i.e., at low damage levels) and in its favor in the area above it. $A$, Resistance achieved by damage avoidance (see text). $B$, Resistance achieved by damage reduction.

weaker competitive effect exerted by the smaller. Under asymmetry, in contrast, the smaller resistant neighbor exerts no counter effect on the larger susceptible plant. The resistant plant thus receives the full brunt of competition, while the larger susceptible plant grows unfettered.

As in the symmetric case, resistant plants can capitalize on the misfortune of their susceptible neighbors and grow larger under high damage levels than they do under low damage. Figure 6 shows the results of 22 simulation runs identical to those used in figure 1 , except that the symmetric competition coefficient, $\theta_{N}$, was replaced by its asymmetric counterpart, $\theta_{\text {asym }}$ (see eq. [6]). At low density, the differences between the asymmetric (fig. 6A) and symmetric (fig. 1A) cases were minor. However, the intense competition at high density amplifies resistance costs so much that the resistant genotype is favored only at the most extreme damage levels (fig. 6B).

For the most part, asymmetric competition amplifies resistance cost so greatly that selection turns against resistance at high density. Figure 7 shows selection against resistance at high densities, as revealed in two sets of 168 runs using the same parameter values as in figure 3 , except for the change in competition mode. The surface for damage avoidance (fig. 7A) is lower at every competitiondamage level than for damage reduction (fig. $7 B$ ), the opposite of the symmetric case.

Resistance is more generally favored by early attack

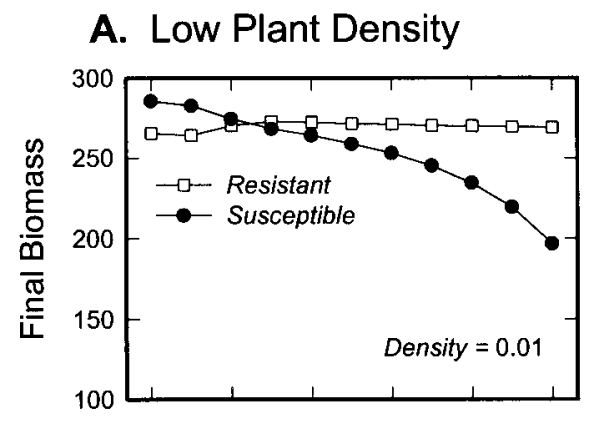

\section{B. High Plant Density}

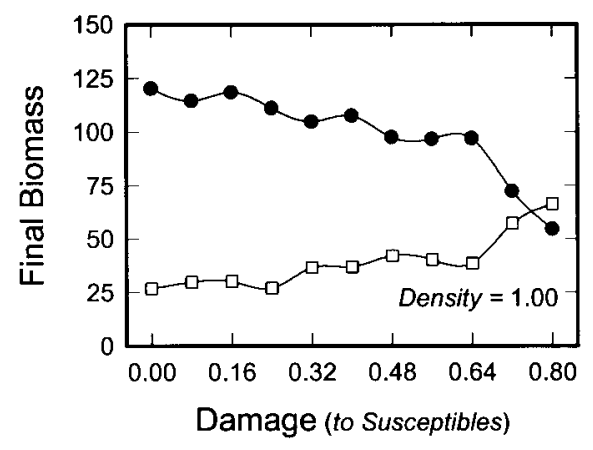

Figure 6: Mean final biomass of resistant and susceptible genotypes exposed to increasing levels of herbivory. Competition is asymmetric. Attack occurred at the 25 time interval. Parameter values as in figure 1. $A$, Competition weak (density $=0.01$ ). $B$, Competition strong (density $=1.0$ ). Under asymmetric competition, preattack resistance costs are compounded so that payback occurred only at very high herbivory levels. 


\section{A. Damage Avoidance}

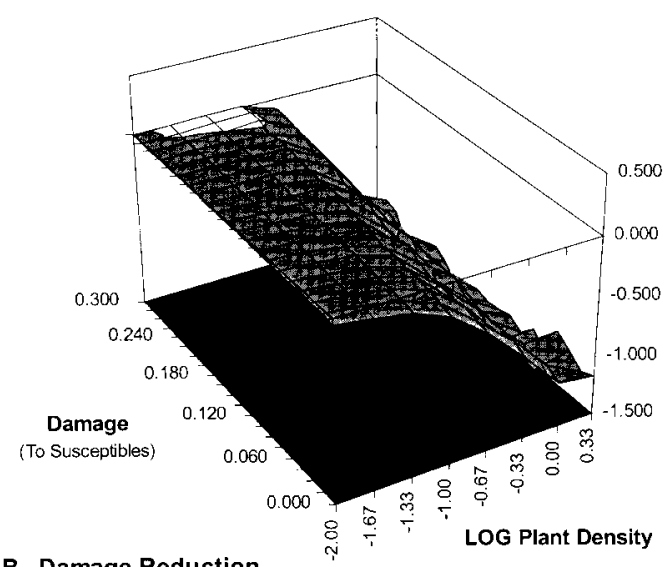

B. Damage Reduction

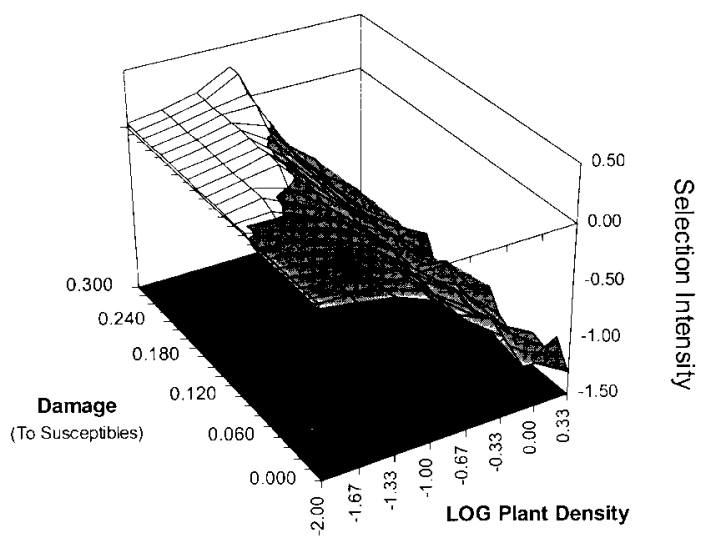

Figure 7: Selective advantage of resistance across a range of densities and herbivory levels. Competition is asymmetric. Parameters as in figure 3. The white areas of the surface denote density-damage combinations where resistance is favored, whereas the shaded areas are those where susceptibility is favored. The white-shade border denotes the payback contour, where benefits and costs are equal. $A$, Resistance achieved by damage avoidance (see text). $B$, Resistance achieved by damage reduction.

when competition is asymmetric (fig. 8). This follows from the early amplification of costs. Only when attack occurs very early, before competition has suppressed resistant plants, will resistants gain a postattack size advantage. When attack is late, the resistants are already so suppressed that they may remain at the bottom of the postattack size hierarchy at all but the most extreme damage levels. As a result, the damage levels required to favor resistance increases with later attack.

The patterns of density-dependent reversal in selection are opposite for the symmetric and asymmetric cases. Symmetric competition amplifies selection in favor of resistance (fig. 3), but asymmetric amplifies selection against resistance (fig. 7).

\section{Induced Resistance}

It has been suggested that induced resistance should be especially favored in competitive environments (Coley 1987; Karban and Baldwin 1997). When resistance is induced, the material costs of producing resistance factors are not paid unless attack actually occurs, (although there could be a cost for maintaining the ability to be induced). We extended the model to see if asymmetric competition favors resistance when costs are delayed until after attack.

Figure 9 shows the selective surface for induced damage reduction resistance under symmetric and asymmetric competition, using the same parameter values as for figures $3 B$ and $7 B$. In these runs, both genotypes grew at the same

\section{A. Damage Avoidance}

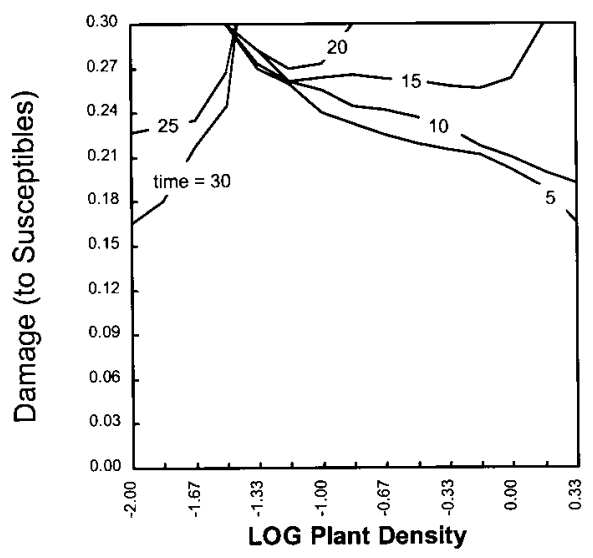

\section{B. Damage Reduction}

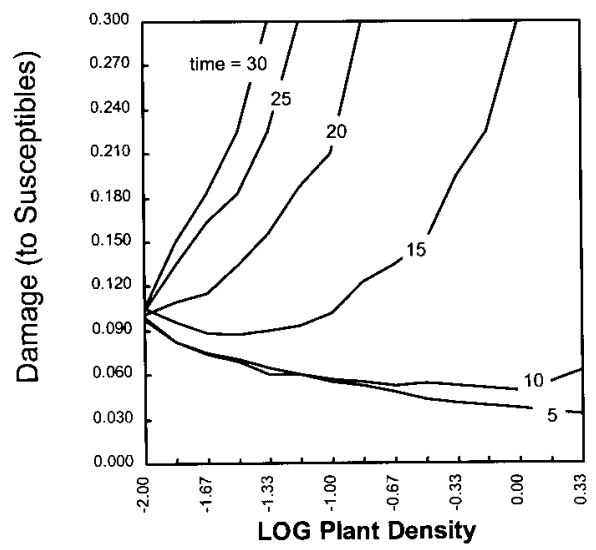

Figure 8: Payback contours when attack occurs at different time intervals. Competition is asymmetric. Parameter values as in figure 7. Selection acts against resistance in the area below each contour (i.e., at low damage levels) and in its favor in the area above it. $A$, Resistance achieved by damage avoidance (see text). $B$, Resistance achieved by damage reduction. 


\section{A. Symmetric Competition}

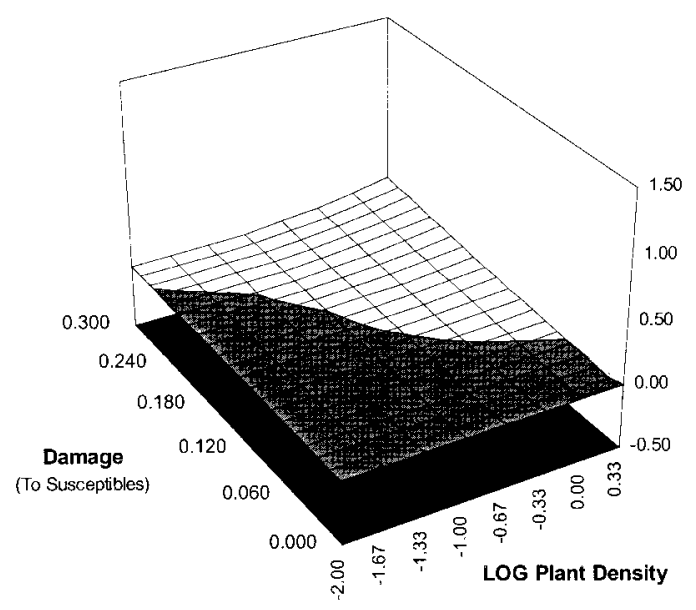

B. Asymmetric Competition

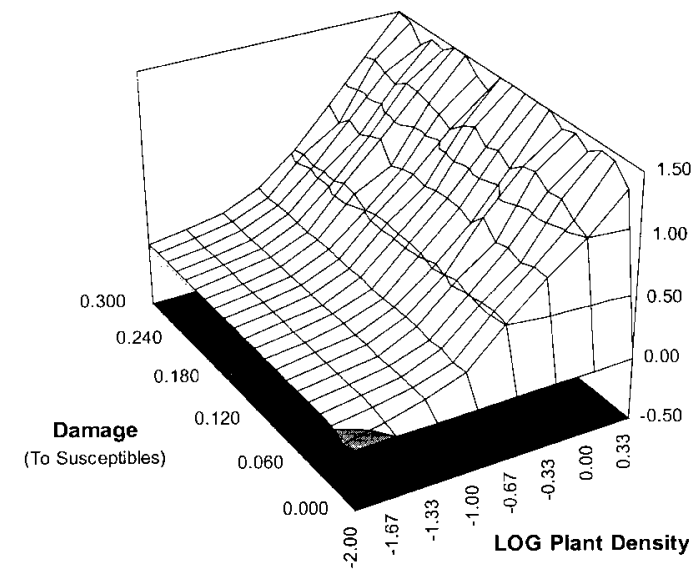

Figure 9: Selective advantage of induced damage reduction resistance across a range of densities and herbivory levels. Parameters as in figures 3 and 7. The white areas of the surface denote density-damage combinations where resistance is favored, whereas the shaded areas are those where susceptibility is favored. The white-shade border denotes the payback contour, where benefits and costs are equal. $A$, Competition is symmetric. $B$, Competition is asymmetric.

rate, $\rho$, during the preattack intervals. When attack occurred, resistance was "turned on" and remained on for the rest of the season.

With symmetric competition, there are only minor quantitative differences in selection between constitutive and induced resistance (cf. fig. $3 B$ with fig. $9 A$ ). In contrast, induced resistance is far more favorable than constitutive resistance under asymmetric competition (fig. $7 B$ vs. fig. $9 B$ ). By eliminating preattack costs, both genotypes remain similar in size until attack. When attack occurs, even minor damage levels put resistant plants at the top of the size hierarchy, where they grow unfettered by the susceptibles.

\section{Discussion}

The model predicted that the fitness effect of resistance varies in intensity and direction with the mode and the intensity of intraspecific competition. At any given herbivory level, an increase in plant density tends to change the fitness differences between resistant and susceptible genotypes; in some cases a slight advantage to resistance is magnified at high density, while in other cases high density magnifies a disadvantage. The change in selection intensity per se is complicated by density-dependent reversals in selection direction that can occur within a given herbivory level. With moderate attack levels the resistant genotype can be inferior at low plant density but superior at high density (fig. 3). In other cases there can be two reversals in the direction of selection along the density gradient (fig. 7). Finally, the sensitivity of selection to density depends on the timing of attack (figs. 5, 8).

Competition mode had a particularly strong influence on the fitness effects of resistance costs and benefits. Switching from size-symmetric to size-asymmetric competition, while holding all else equal, could reverse the relative fitness of resistant and susceptible genotypes. The different effects of symmetric and asymmetric competition modes lie in the fact that the latter causes stronger size hierarchies earlier in the season than the former. The early asymmetric competition puts the slower growing resistant plants at a great size disadvantage by the time of attack. Once this strong hierarchy was established, only the highest herbivory levels and strongest resistance could reverse the relative sizes of resistants and susceptibles. More often, the early negative effects of costs did not repay the benefits of defense from herbivory.

Conventional wisdom might hold that damage early in the life history, during exponential growth, will be the most detrimental and so defense at this point in time will be more strongly favored by selection. At first glance this seems to be born out under asymmetric competition, but in this case early defense is favored simply because early attack on susceptibles is the only way for resistants to make it to the top of the size hierarchy. The conventional wisdom may be flawed because a given proportion of tissue lost during the exponential phase may be easy to replace. Later, when maintenance costs and self-shading slow the growth rate, losing that same proportion of tissue may be disastrous because of the greater time required for its replacement. Of course, if the absolute amount of tissue lost is the same, early attack may have more profound effects-a grasshopper's bite will be more detrimental to a seedling than to a tree-but only because the early damage is 
so much greater on a proportional basis. Finally, these results pertain to damage before reproduction begins. Postreproductive attack should have no effect on fitness, and so resistance at this point provides no benefit.

Given the diversity of outcomes seen in this simplified model, it should be no surprise that experiments testing the combined effects of competition and herbivory on plant performance have found a diversity of results. As we stated in the introduction, many experiments have revealed compounding effects of herbivory on competition between attacked and unattacked plant types. Other studies have not found such effects. Some of these "null" results may simply reflect the inherent limitations in any empirical study. Several studies that fail to show compounding effects of herbivory and competition may not have included damage or density levels sufficient to find them. The work by Karban (1993) is a case in point. In this field experiment, Karban tested for a cost to an induced resistance factor in the shrub Gossypium. Although no costs are apparent under benign growing conditions, he hypothesized that competition could intensify costs to detectable levels. He induced the defense in plants growing at two plant densities: a control where plants were left at ambient densities, and a reduced-density treatment, where conspecifics were cleared from around the focal plants. Although the data suggested that competition intensified costs, they were not statistically significant. Wisely, Karban did not conclude that defense costs are absent but rather-after performing a power analysis of the experiment-that any costs that may exist cannot be very large. It seems reasonable to think that compounded costs might have been revealed had it been possible to augment plant density to above-ambient levels.

Our results offer an explanation for a puzzling result presented by Bentley and Whittaker (1979). They found that the effects of grazing and competition were subadditive, that is, their combined negative effects on final plant size were less than the sum of each individually (Bentley and Whittaker 1979, experiment 3). Their experiment examined the effect of grazing by the beetle Gastrophysa on the interaction between the faster-growing, competitively superior Rumex obtusifolius and the slowergrowing Rumex crispus. Although they examined interspecific competition, the close phylogenetic relationship between the two species makes this study closely allied to our two-genotype model. In this system competition may be asymmetrical; the final biomass of $R$. crispus in competition with its conspecific was only $31 \%$ as great as without, whereas final biomass of $R$. obtusifolius was hardly affected by competition. The beetle oviposits and feeds preferentially on the faster-growing plant, and so $R$. $o b$ tusifolius and $R$. crispus correspond to the susceptible and resistant genotypes, respectively, in our model. Although one could interpret the subadditive result to mean that $R$. crispus is so strongly suppressed by competition that the addition of herbivory had little further effect, we suggest that the higher herbivory on the superior competitor may have opened the canopy enough to partially relieve $R$. crispus, the inferior competitor, from suppression. As a result, $R$. crispus gets a small gain through the misfortune of its neighbor, even if it is not sufficient to reverse its inferior position. Figure 7 shows such an effect is possible under asymmetric competition.

\section{Alternative Model Assumptions}

The outcome of any model is determined by its assumptions, and so some alternative assumptions and their potential effects should be considered. For instance, base parameter values (i.e., competition coefficient, resistance levels, and costs) did not vary with plant age, although that need not be true. We also assumed that plants were exposed to a single attack. Violation of either assumption would influence the standing of the two genotypes in the size hierarchy, the ability to regrow, and the time available for recovery. Further, our two extreme types of resistance, damage avoidance and damage reduction, are caricatures of attack patterns in natural populations, as is the dichotomous classification of competition as size-symmetric or size-asymmetric (Law et al. 1996; Schwinning and Weiner 1998). However, we would argue that the model illustrates the principles by which growth rate, selflimitation, competition, damage, and costs interact to affect selection on resistance and further argue that the extreme scenarios examined here bracket the possible qualitative outcomes, except as noted below.

We assumed that the costs of resistance were manifested through reduced growth, but other sorts of costs have been noted. For instance, when multiple enemies attack a plant species, increasing the resistance to one could increase susceptibility to others (Maddox and Root 1990; Linhart 1991; Simms 1992; Hougen-Eitzman and Rausher 1994; van der Meijden 1996). Although this presents a more complicated situation, the principles of this model should still apply. Less clear is how they would apply to a situation, such as shown by Beirie and Antonovics (1996), where resistance costs are manifest in delayed maturation.

The model assumptions that most affect our qualitative predictions concern resource requirements. Although resource dynamics are not explicitly modeled, we make the implicit assumption that resource consumption per unit biomass is the same for both resistant and susceptible genotypes and for both damaged and undamaged individuals. Thus, there is no trade-off between resistance and basic competitive ability. Without this trade-off, we did not find frequency-dependent changes in the direction of 
selection. Ecological models by Holt et al. (1994) and Grover (1995) that assume such a trade-off suggest that resistant and susceptible genotypes could be maintained in a balance polymorphism through frequency-dependent selection.

A second implicit assumption is that the same resources limit growth under all conditions. However, if different resources limit growth under high density conditions than low, the negative effects of damage may not be amplified by competition. Parmesan (2000) suggested that an unusual result from a study of Colinsia torreyi could be explained if a different resource limits growth in high-density patches than in low-density ones. Her experiment compared fitness achieved by damaged and undamaged focal plants in low- and high-density plant neighborhoods; all neighbors were undamaged (cf. the Bentley and Whittaker 1979 experiment). Competition per se caused a measurable fitness loss. Defoliation caused an additional fitness loss in the low-density neighborhoods, but surprisingly, defoliation caused no further fitness decrement in the high density neighborhoods-once suppressed by competition, plants were no longer sensitive to damage. Parmesan suggested that defoliation had no effect at high plant density because water limited growth in these neighborhoods. If soil moisture gets depleted in crowded areas, leaf photosynthetic capacity may become unused, and so loss of leaf area will have inconsequential effects on productivity. However, leaf damage has a significant fitness effect at low density, she reasoned, because there are fewer plants to consume water, and so photosynthesis stays limited by light capture. If this explanation is correct, one might expect that fitness effects of root herbivory would be magnified by competition when water is limiting, while effects of foliar herbivory are amplified when light is limiting. Therefore, our model applies to the situation where the consumed tissue is responsible for gathering the limiting resource.

\section{Competition and the Evolutionary Dynamics of Resistance: Some Further Issues}

We have presented a model that evaluates relative fitness of alternate genotypes under an array of conditions in a single generation. As such, we mimicked the types of experiments that population biologists perform on the costs and benefits of plant resistance. However, the prediction that competition induces a density-dependent component to selection suggests that the evolutionary dynamics of resistance may be more complex than indicated by some of the guiding theories of plant-herbivore interactions (e.g., Coley et al. 1985; Price 1991; Herms and Matson 1992). Although these theories may give an indication of what happens at equilibrium, density-dependent selection can cause evolution to take complex paths to equilibrium and in some cases may prevent an equilibrium from being reached (Fryxell and Lundberg 1997; Law et al. 1997). It is possible that as resistance spreads in a population, the carrying capacity for specialized herbivore populations will decline. This in turn could allow the plant population to expand but could also relieve selection pressure for resistance and allow susceptibility to rebound. Whether or not this results in a rebound of the herbivore populations, and the selection they impose, is not easy to predict. If herbivores themselves also evolve in response to plant resistance, the possibilities can be quite complex.

Numerous factors are known to be influential in models of victim evolution and exploiter-victim coevolution. These include host range (Takasu 1998), community interactions among herbivores (Hougen-Eitzman and Rausher 1994), genetic systems of resistance (Frank 1993, 1994; Hochberg and van Baalen 1998), feeding preferences (Tuomi and Augner 1993; Augner 1994), multiple forms of resistance (Frank 1993; Hochberg 1997; Tiffen 2000), habitat suitability (Hochberg and Holt 1995; Hochberg and van Baalen 1998), migration (Frank 1997; Hochberg and van Baalen 1998), and mutation (Kawecki et al. 1997). We believe that the importance of competition mode, resistance type, and timing of attack in our study merit their attention in a fully evolutionary model framework.

\section{Acknowledgments}

Helpful suggestions were given to us by A. Beirie, P. Klinkhammer, and P. van Tienderen as this work progressed. We thank T. E. Miller, E. van der Meijden, W. van Putten, and several anonymous reviewers for comments that helped us improve on previous drafts of the manuscript. Support for A.E.W. came through grants from the Koninklijke Nederlandse Akademie van Wetenschappen and the National Science Foundation (DEB-9915873) and for M.E.H. through the Ministère de l'Enseignement Supèrieure et de le Recherche Scientifique of France.

\section{Literature Cited}

Augner, M. 1994. Should a plant always signal its defense against herbivores? Oikos 70:322-332.

Augner, M., T. Fagerstrom, and J. Tuomi. 1991. Competition, defense and games between plants. Behavioral Ecology and Sociobiology 29:231-234.

Augner, M., J. Tuomi, and M. Rout. 1997. Effects of defoliation on competitive interactions in European white birch. Ecology 78:2369-2377.

Basey, J. M., and S. H. Jenkins. 1993. Production of chemical defenses in relation to plant growth rate. Oikos 68: 323-328.

Beirie, A., and J. Antonovics. 1996. Sex-specific costs of 
resistance to the fungal pathogen Ustilago violacea ( $M i-$ crobotryum violaceum) in Silene alba. Evolution 50: 1098-1110.

Bentley, S., and J. B. Whittaker. 1979. Effects of grazing by a chrysomelid beetle, Gastrophysa viridula, on competition between Rumex obtusifolius and Rumex crispus. Journal of Ecology 67:79-90.

Bergelson, J. 1994. The effects of genotype and the environment on costs of resistance in lettuce. American Naturalist 143:349-359.

Bergelson, J., and C. B. Purrington. 1996. Surveying patterns in the cost of resistance in plants. American Naturalist 148:536-558.

Bonan, G. B. 1991. Density effects on the size structure of annual plants populations: an indication of neighborhood competition. Annals of Botany 68:341-347.

Burdon, J. J., R. H. Groves, P. E. Kaye, and S. S. Speer. 1984. Competition in mixtures of susceptible and resistant genotypes of Chondrilla juncea differentially infected with rust. Oecologia (Berlin) 64:199-203.

Clay, K. 1990. The impact of parasitic and mutualistic fungi on the competitive interactions among plants. Pages 391-412 in J. Grace and D. Tilman, eds. Perspectives in plant competition. Academic Press, New York.

Coley, P. 1987. Interspecific variation in plant antiherbivore properties: the role of habitat quality and rate of disturbance. New Phytologist 106(suppl.):251-263.

Coley, P., J. P. Bryant, and F. S. Chapin. 1985. Resource availability and plant anitherbivore defense. Science (Washington, D.C.) 230:895-899.

Cottam, D. A. 1986. The effects of slug grazing on Trifolium repens and Dactylis glomerata in monoculture and mixed sward. Oikos 47:275-279.

Cottam, D. A., J. B. Whittaker, and A. J. C. Malloch. 1986. The effects of chrysomelid beetle grazing and plant competition on growth of Rumex obtusifolius. Oecologia (Berlin) 70:452-456.

Crawley, M. J. 1983. Herbivory: the dynamics of animalplant interactions. University of California Press, Berkeley.

Dytham, C., and B. Shorrocks. 1995. Aggregation and the maintenance of genetic diversity: an individual-based cellular model. Evolutionary Ecology 9:508-519.

Edenius, L., K. Danell, and R. Bergstrom. 1993. Impact of herbivory and competition on compensatory growth in woody plants: winter browsing by moose on Scots pine. Oikos 66:286-292.

Fowler, N. L., and M. D. Rausher. 1985. Joint effects of competitors and herbivores on growth and reproduction in Aristolochia reticulata. Ecology 66:1580-1587.

Frank, S. A. 1993. Evolution of host-parasite diversity. Evolution 47:1721-1732.
- 1994. Coevolutionary genetics of hosts and parasites with quantitative inheritance. Evolutionary Ecology 8:74-94.

- 1997. Spatial processes in host-parasite genetics. Pages 325-352 in I. Hanski and M. Gilpin, eds. Metapopulation biology: ecology, genetics, and evolution. Academic Press, New York.

Frost, I., and H. Rydin. 1997. Effects of competition, grazing and cotyledon nutrient supply on growth of Quercus robur seedlings. Oikos 79:53-58.

Fryxell, J. M., and P. Lundburg. 1997. Individual behavior and community dynamics. Chapman \& Hall, London.

Goldberg, D. E. 1987. Neighborhood competition in an old-field community. Ecology 68:1211-1223.

Grove, R. H., and J. D. Williams. 1975. Growth of skeleton weed (Chondrilla juncea L.) as affected by growth of subterranean clover (Trifolium subterraneum) and infection by Puccinia chondrilla Bubak \& Syd. Australian Journal of Agricultural Research 26:975-983.

Grover, J. P. 1995. Competition, herbivory, and enrichment: nutrient-based models for edible and inedible plants. American Naturalist 145:746-774.

Harper, J. L. 1977. Population biology of plants. Academic Press, New York.

Herms, D. A., and W. J. Matson. 1992. The dilemma of plants: to grow or defend. Quarterly Review of Biology 67:283-336.

Hjalten, J., K. Danell, and L. Ericson. 1993. Effects of simulated herbivory and intraspecific competition on the compensatory ability of birches. Ecology 74: 1136-1142.

Hochberg, M. E. 1997. Hide or fight? the competitive evolution of concealment and encapsulation in hostparasitoid associations. Oikos 80:342-352.

Hochberg, M. E., and R. D. Holt. 1995. Refuge evolution and the population dynamics of coupled hostparasitoid associations. Evolutionary Ecology 9: 633-661.

Hochberg, M. E., and M. van Baalen. 1998. Antagonistic coevolution along environmental gradients. American Naturalist 152:620-634.

Holt R. D., J. Grover, and D. Tilman. 1994. Simple rules for interspecific dominance in systems with exploitative and apparent competition. American Naturalist 144: 741-771.

Hougen-Eitzman, D., and M. D. Rausher. 1994. Interactions between herbivorous insects and plant-insect coevolution. American Naturalist 143:677-697.

Hunt, R., and J. H. C. Cornelissen. 1997. Components of relative growth rate and their interrelations in 59 temperate plant species. New Phytologist 135:395-417.

Iwasa, Y., and T. Kubo. 1997. Optimal size of storage for 
recovery after unpredictable disturbances. Evolutionary Ecology 11:41-65.

Karban, R. 1993. Costs and benefits of induced resistance and plant density of a native shrub, Gossypium thurberi. Ecology 74:9-19.

Karban, R., and I. T. Baldwin. 1997. Induced responses to herbivory. University of Chicago Press, Chicago.

Kawecki, T. J. 1997. Sympatric speciation via habitat specialization driven by deleterious mutations. Evolution 51:1751-1763.

Kelly, J. K. 1996. Kin selection in the annual plant Impatiens capensis. American Naturalist 147:899-918.

Kraaijveld, A. R., and H. C. J. Godfray. 1997. Trade-off between parasitoid resistance and larval competitive ability in Drosophila melanogaster. Nature (London) 389:278-280.

Law R., P. Marrow, and U. Dieckmann. 1997. On evolution under asymmetric competition. Evolutionary Ecology 11:485-501.

Lee, T. D., and F. A. Bazzaz. 1980. Effects of defoliation and competition on growth and reproduction in the annual plant Abutilon theophrasti. Journal of Ecology 68:813-821.

Lenski, R. E. 1988. Experimental studies of pleiotropy and epistasis in Eschericha coli: variation in competitive fitness among mutants resistant to virus T4. Evolution 42: 425-432.

Linhart, Y. B. 1991. Disease, parasitism and herbivory: multidimensional challenges in plant evolution. Trends in Ecology \& Evolution 6:392-396.

Lively, C. M., S. G. Johnson, L. F. Delph, and K. Clay. 1995. Thinning reduces the effect of rust infection on jewelweed (Impatiens capensis). Ecology 76:1895-1862.

Louda S. M., K. H. Keeler, and R. D. Holt. 1990. Herbivore influences on plant performance and competitive interactions. Pages 413-444 in J. Grace and D. Tilman, eds. Perspectives in plant competition. Academic Press, New York.

Maddox G. D., and R. B. Root. 1990. Structure of the encounter between goldenrod (Solidago altissima) and its diverse insect fauna. Ecology 71:2115-2124.

Marbry C. M., and P. W. Wayne. 1997. Defoliation of the annual herb Abutilon theophrasti: mechanisms underlying reproductive compensation. Oecologia (Berlin) 111:225-232.

Maron, J. 1997. Interspecific competition and insect herbivory reduce bush lupine (Lupinus arboreus) seedling survival. Oecologia (Berlin) 110:284-290.

Maschinski, J., and T. G. Whitham. 1989. The continuum of responses to herbivory: the influence of plant association, nutrient availability, and timing. American Naturalist 134:1-19.

McEvoy, P. B., N. T. Rudd, C. S. Cox, and M. Huso. 1993.
Disturbance, competition, and herbivory effects on ragwort Senecio jacobaea populations. Ecological Monographs 63:55-75.

Miller, T. E., and J. Weiner. 1989. Local density variation may mimic effects of asymmetric competition on plant size variability. Ecology 70:1188-1191.

Mitchel-Olds, T., and D. Bradely. 1996. Genetics of Brassica rapa. 3. Costs of disease resistance to three fungal pathogens. Evolution 50:1859-1865.

Mutikainen, P., and M. Walls. 1995. Growth, reproduction and defence in nettles: responses to herbivory modified by competition and fertilization. Oecologia (Berlin) 104: 487-495.

Niemann, G. J., J. B. M. Pureveen, G. B. Eijkel, and H. Poorter. 1995. Differential chemical allocation and plant adaptation: a PY-MS study of 24 species differing in relative growth rate. Plant and Soil 175:275-289.

Notzold, R., B. Blossey, and E. Newton. 1998. The influence of below ground herbivory and plant competition on growth and biomass allocation of purple loosestrife. Oecologia (Berlin) 113:82-93.

Oesterheld, M., and S. J. McNaughton. 1991. Effects of stress and time for recovery on the amount of compensatory growth after grazing. Oecologia (Berlin) 85: 305-313.

Paige, K. N., and T. G. Whitham. 1987. Overcompensation in response to mammalian herbivory: the advantage of being eaten. American Naturalist 228:407-416.

Parker M. A., and A. G. Salzman. 1985. Herbivore exclosure and competitor removal: effects of juvenile survivorship and growth in the shrub Guterrezia microcephala. Journal of Ecology 73:903-913.

Parmesan, C. 2000. A novel response to crossed competition and herbivory treatments in a wild annual. Journal of Ecology (in press).

Price, P. W. 1991. The plant vigor hypothesis and herbivore attack. Oikos 62:244-251.

Price, P. W., M. Westoby, B. Rice, P. Atsatt, R. S. Fritz, J. N. Thompson, and K. Mobley. 1986. Parasite mediation of ecological interactions. Annual Review of Ecology and Systematics 17:487-505.

Rausher, M. D., and P. P. Feeny. 1980. Herbivory, plant density and plant reproductive success: the effects of Battus philanor on Aristilochia reticulata. Ecology 61: 905-917.

Reader, R. J. 1992. Herbivory as a confounding factor in an experiment measuring competition among plants. Ecology 73:373-376.

Sagers, C. L., and P. D. Coley. 1995. Benefits and costs of defense in a neotropical shrub. Ecology 76:1835-1843.

Schmitt, J., and D. W. Ehrhardt. 1990. Enhancement of inbreeding depression by dominance and suppression in Impatiens capensis. Evolution 44:269-278. 
Schwinning, S., and J. Weiner. 1998. Mechanisms determining the degree of size asymmetry in competition among plants. Oecologia (Berlin) 113:447-455.

Shabel, A. B., and D. R. Peart. 1994. Effects of competition, herbivory and substrate disturbance on growth and size structure in pin cherry (Prunus pensylvanica) seedlings. Oecologia (Berlin) 98:150-158.

Simms, E. L. 1992. Costs of plant resistance to herbivores. Pages 392-425 in R. F. Fritz and E. L. Simms, eds. Plant resistance to herbivores and pathogens: ecology, evolution, and genetics. University of Chicago Press, Chicago.

Steinger, T., H. Muller-Scharer. 1992. Physiological and growth responses of Centaurea-maculosa (Asteraceae) to root herbivory under varying levels of interspecific plant competition and soil nitrogen availability. Oecologia (Berlin) 91:141-149.

Sun, D. 1992. Trampling resistance, recovery and growth rate of 8 plant species. Agriculture, Ecosystems and Environment 15:265-273.

Takasu, F. 1998. Why do all host-species not show defense against avain brood parasites: evolutionary lag or equilibrium? American Naturalist 151:193-205.

Tiffen, P. 2000. Are tolerance, avoidance, and antibiosis evolutionarily and ecologically equivalent responses of plants to herbivores? American Naturalist 155:128-138.

Tuomi, J., and M. Augner. 1993. Synergistic selection of unpalatability in plants. Evolution 47:668-672.

van Dam, N., and I. T. Baldwin. 1998. Costs of jasmonateinduced responses in plants competing for limited resources. Ecology Letters 1:30-33. van der Meijden, E. 1996. Plant defense and evolutionary dilemma: contrasting effects of (specialist and generalist) herbivores and natural enemies. Entomologia Experimentalis et Applicata 80:307-310.

van der Putten, W. H., and B. A. S. Peters. 1997. How soil-borne pathogens may affect plant competition. Ecology 78:1785-1795.

Verwijst, T. 1993. Influence of the pathogen Melampsora epitea on intraspecific competition in a mixture of Salix viminalis clones. Journal of Vegetation Science 4: 717-722.

Vrieling, K., and C. A. M. van Wijk. 1994. Estimating costs and benefits of the pyrrolizidine alkaloids of Senecio jacobaea under natural conditions. Oikos 70:449-454.

Weiner, J. 1985. Size hierarchies in experimental populations of annual plants. Ecology 66:743-752.

- 1990. Asymmetric competition in plant populations. Trends in Ecology \& Evolution 5:360-364.

Williams, M. M., II, N. Jordan, and C. Yerkes. 1995. The fitness cost of triazene resistance in jimsonweed (Datura stramonium L.). American Midland Naturalist 133: 131-137.

Windel, P. N., and E. H. Franz. 1979. The effects of insect parasitism on plant competition: greenbugs and barley. Ecology 60:521-529.

Zangerl, A. R., and F. A. Bazzaz. 1992. Theory and pattern in plant defense allocation. Pages 363-391 in R. F. Fritz and E. L. Simms, eds. Plant resistance to herbivores and pathogens: ecology, evolution, and genetics. University of Chicago Press, Chicago.

Associate Editor: Thomas E. Miller 